\title{
Large Parenchymal Perianeurysmal Cyst: A Case Report
}

\author{
Gyani J.S. Birua ${ }^{1}$ Gaurav Tyagi ${ }^{1}$ Manish Beniwal ${ }^{1}$ \\ ${ }^{1}$ Department of Neurosurgery, National Institute of Mental Health \\ and Neurosciences (NIMHANS), Bengaluru, Karnataka, India \\ 2 Department of Neuropathology, National Institute of Mental Health \\ and Neurosciences (NIMHANS), Bengaluru, Karnataka, India
}

\author{
Dwarakanath Srinivas $^{1}$ Shilpa Rao ${ }^{2}$
}

J Neurosci Rural Pract 2021;12:800-803.

\begin{abstract}
Address for correspondence Manish Beniwal, MS, MCh, Department of Neurosurgery, National Institute of Mental Health and Neurosciences (NIMHANS), Faculty Building, 2nd Floor, Bengaluru, Karnataka 560029, India (e-mail: beniwal.m@gmail.com).
\end{abstract}

\begin{abstract}
Parenchymal perianeurysmal cysts are rare. We report a case of 50-year-old woman who presented with persistent headaches and episodes of vomiting for the last 2 months. Magnetic resonance imaging of the brain showed a well-defined solitary cystic lesion with a mural nodule measuring $5.4 \times 5.2 \times 4.6 \mathrm{~cm}$ in the right basifrontal region. The mural nodule was cortically based. It was hypointense on T2-weighted fluidattenuated inversion recovery and showed intense contrast enhancement with few nonenhancing areas-no evidence of diffusion restriction. The cyst wall was nonenhancing, and magnetic resonance angiogram was unremarkable. Differential diagnoses included intra-axial gliomas such as ganglioglioma and pleomorphic

Keywords

- intracranial

- aneurysm

- perianeurysmal cyst

- surgery xanthoastrocytoma. Right pterional craniotomy and a transcortical approach were made. Subtotal excision of cyst and clipping of right middle cerebral artery bifurcation thrombosed aneurysm were done. After 6 months of follow-up, patient is stable without any deficits. A parenchymal perianeurysmal cyst is a rare entity; it is crucial to be considered a differential diagnosis in any cystic lesion with the mural nodule.
\end{abstract}

\section{Introduction}

Cyst formation is seen in various intracranial pathologies ranging from congenital or acquired to infectious or tumor related. ${ }^{1}$ Occasionally, cyst formation is also seen in cavernous angiomas ${ }^{2,3}$ and arteriovenous malformation., ${ }^{4,5}$ However, the development of cyst in the cerebral aneurysm is rare. ${ }^{6-8}$ We report a case of a fully thrombosed right middle cerebral artery (MCA) aneurysm with parenchymal perianeurysmal cyst with features of mass effect.

\section{Case Report}

A 50-year-old woman presented to the emergency ward with a history of persistent headache and vomiting episodes. A computed tomography scan of the brain disclosed a right frontal hypodense cystic lesion with isodense intracystic nodule with specks of hyperdensity at the nodule's periphery. The lesion was causing compression of frontal horn and foramen of Monro with dilatation of the contralateral occipital horn with subfalcine herniation (-Fig. 1A, B). Magnetic resonance imaging (MRI) and magnetic resonance angiography (MRA) of the brain were done to rule out the malignant space-occupying lesion. MRI showed a well-defined solitary cystic lesion with a mural nodule measuring $5.4 \times 5.2 \times 4.6 \mathrm{~cm}$ in the right basifrontal. The mural nodule was cortical based in the basifrontal region. It was hypointense on T2-weighted fluid-attenuated inversion recovery and showed intense contrast enhancement with few nonenhancing areas with no diffusion restriction evidence. The cyst wall was nonenhancing, and MRA was unremarkable. Differential diagnosis included published online September 7, 2021
DOI https://doi.org/ 10.1055/s-0041-1735243. ISSN 0976-3147.

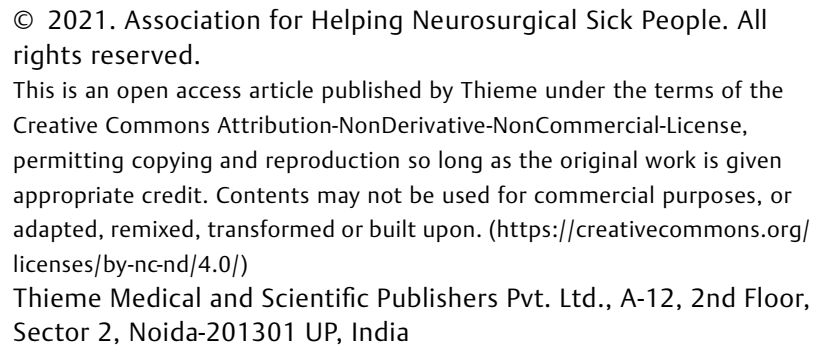

This is an open access article published by Thieme under the terms of the Creative Commons Attribution-NonDerivative-NonCommercial-License, permitting copying and reproduction so long as the original work is given appropriate credit. Contents may not be used for commercial purposes, or adapted, remixed, transformed or built upon. (https://creativecommons.org/ licenses/by-nc-nd/4.0/)

Thieme Medical and Scientific Publishers Pvt. Ltd., A-12, 2nd Floor, Sector 2, Noida-201301 UP, India 

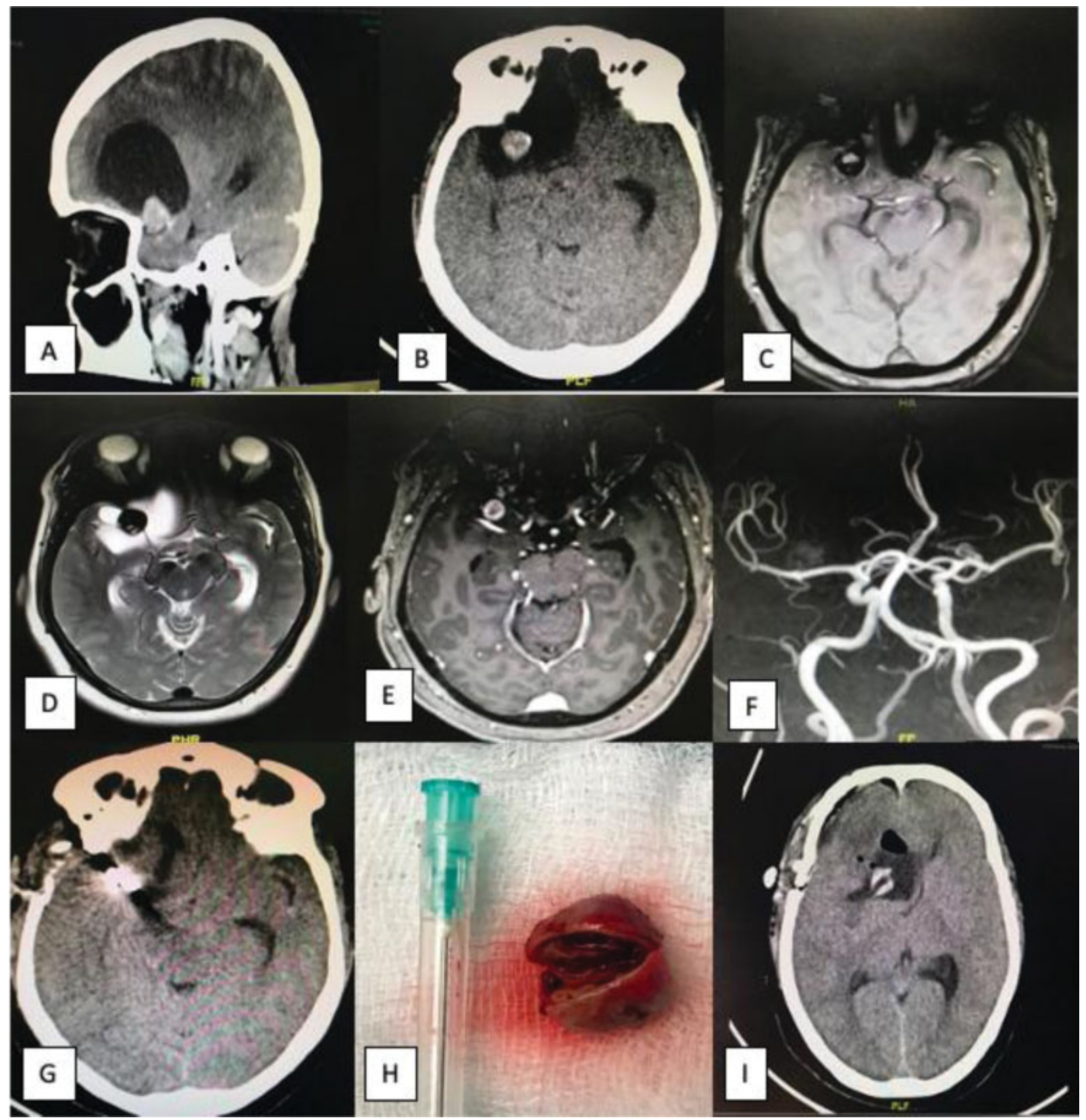

Fig. 1 (A, B) CT scan of the brain, sagittal and axial sections shows right frontal hypodense cystic lesion with isodense intracystic nodule with specks of hyperdensity at the periphery of a nodule. (C) MRI (FLAIR), axial section images show right frontal isointense lesion with isointense to hyperintense intracystic nodule. (D) T2-weighted MRI, axial section shows a right frontal hyperintense lesion with the intracystic hypointense nodule. (E) MRI of the brain with contrast shows enhancement of intracystic nodule at right frontal region. (F) MR angiogram is unremarkable. (G) Postoperative CT scan of the brain, axial section, shows aneurysm clip in situ at right frontal region. (H) Resected aneurysm shows thrombus inside the aneurysm. (I) Postoperative follow-up CT scan of the brain, axial section, shows right frontal mixed density area with pneumocephalus. $\mathrm{CT}$, computed tomography; FLAIR, fluid-attenuated inversion recovery; MR, magnetic resonance; MRI, magnetic resonance imaging.

intra-axial glioma such as ganglioglioma, pleomorphic xanthoastrocytoma (-Fig. 1C-F).

Because of a large cystic lesion causing subfalcine herniation and vomiting episodes with persistent headache, the patient was taken up urgently for surgery. Under general anesthesia, subtotal excision of the cyst was done by the right pterional and transcortical approaches. We found clear fluid in the cyst and no apparent communication between the subarachnoid space and cyst. Inside the cyst, a complete thrombosed MCA aneurysm $(1.32 \mathrm{~cm})$ was found. The aneurysm neck was clipped, and the aneurysm was excised (-Fig. 1G, H). Histopathological examination confirmed the lesion to be the aneurysm (-Fig. 2A, B). On review, after 3 months, the patient is stable without any neurological deficits (-Fig. 11).

\section{Discussion}

Sato et al defined a perianeurysmal cyst $(2000)^{7}$ as a structure with signal intensity and attenuation characteristics 


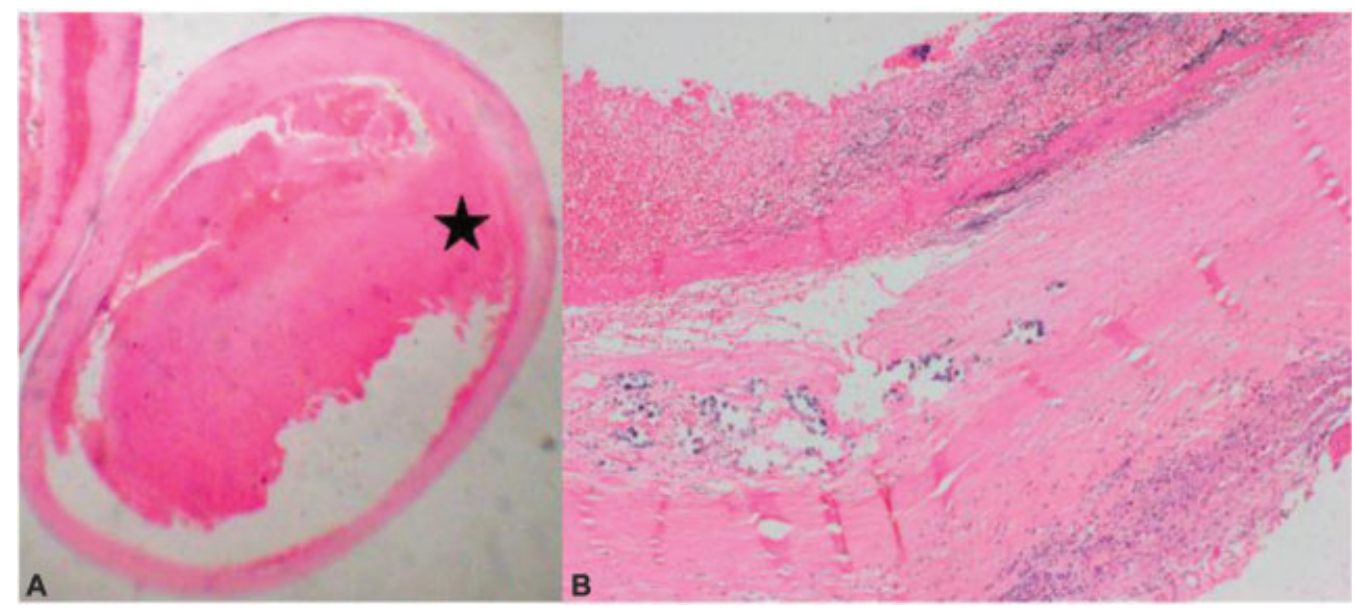

Fig. 2 (A) Dilated vessel with a thrombus in the lumen (hematoxylin and eosin [H\&E], $\times 125$ ). (B) Secondary changes in the wall, inflammatory infiltrates and calcification $(H \& E, \times 200) . \star$ represents "thrombus."

compatible with fluid that lay within the parenchyma adjacent to the aneurysm that did not communicate with the ventricles or cisternal spaces. The development of cyst surrounding an aneurysm is rare, and only 16 cases have been reported in English language literature, ${ }^{1,6-15}$ with the largest case series of five by Sato et al $(2000) .{ }^{7}$ The case of the perianeurysmal cyst was described by Hirota et al (1999) in a man with a previous history of subarachnoid hemorrhage (SAH). ${ }^{6}$

The mechanism of the development of these cysts is not clear. There are four theories proposed to explain cyst's development, but no definitive evidence exists in the literature to favor one over the other. Direct exudation theory has been used to explain the evolution of cyst. The inflammatory mediators' level was increased in the aneurysmal wall, which eventually causes exudation through a "leaky" membrane. ${ }^{13}$ Many investigators believe that disintegrations of blood byproduct due to recurrent hemorrhage through ruptured aneurysm causes development and enlargement of cyst. ${ }^{6}$ History of previous SAH was reported in patients of Hirota et al (1999), ${ }^{6}$ two patients of Sato et al (2000), ${ }^{7}$ and Takai et al (2001). ${ }^{8} \mathrm{~A}$ third theory proposed by Friedman et $\mathrm{al}^{10}$ says that cystic degeneration of ischemic parenchyma causes perianeurysmal cyst formation. The fourth theory says that abnormal cerebrospinal fluid (CSF) circulation causes local CSF entrapment around aneurysm, leading to gradual enlargement of cyst. ${ }^{10}$ But none of these theories satisfactorily explained all the cases reported before.

Perianeurysmal cyst formation has also been seen in postendovascular-treated patients. ${ }^{10,14-16}$ In many patients, perianeurysmal cyst formation was associated with thrombosed aneurysm ${ }^{6-9,13}$ which is present in our case as well.

Different methods were employed for the management of cyst. ${ }^{9}$ Due to the rarity of the entity, no definitive protocol for management has been described yet.

\section{Conclusion}

Perianeurysmal cyst requires treatment. We wish to increase awareness regarding a rare possible differential diagnosis of cystic lesions with the mural nodule so that inadvertent consequences could be avoided during surgical management of such cases in centers where exposures to such cases are limited.

\section{Funding \\ None.}

Conflict of Interest

None declared.

\section{References}

1 Pedro KM, Sih IM. Perianeurysmal parenchymal cyst of the pons: a case report and review of literature. Interdiscip Neurosurg 2020; 21:100731

2 Bellotti C, Medina M, Oliveri G, Barrale S, Ettorre F. Cystic cavernous angiomas of the posterior fossa. Report of three cases. J Neurosurg 1985;63(05):797-799

3 Gangemi M, Longatti P, Maiuri F, Cinalli G, Carteri A. Cerebral cavernous angiomas in the first year of life. Neurosurgery 1989; 25(03):465-468, discussion 468-469

4 Hatashita S, Tajima A, Takeuchi K, Ueno H. Arteriovenous malformation associated with a large cyst-case report. Neurol Med Chir (Tokyo) 1995;35(06):377-379

5 Itakura T, Takifuji K, Ozaki F, et al. Cystic arteriovenous malformation. a case report. Acta Neurochir (Wien) 1989;96; (3-4):154-158

6 Hirota N, Ueno J, Naitoh H, et al. Giant aneurysm associated with a large cyst. Case illustration J Neurosurg 1999;91(01):160

7 Sato N, Sze G, Awad IA, Putman CM, Shibazaki T, Endo K. Parenchymal perianeurysmal cystic changes in the brain: report of five cases. Radiology 2000;215(01):229-233

8 Takai K, Nishihara T, Nemoto S, et al. Multilocular cystic lesion associated with a giant aneurysm. J Neurosurg 2001;95(06): 1081-1081

9 Benvenuti L, Gagliardi R, Scazzeri F, Gaglianone S. Parenchymal perianeurysmal cyst in the brain: case report. Neurosurgery 2006;58(04):E788, discussion E788

10 Friedman JA, McIver JI, Collignon FP, Nichols DA, Piepgras DG. Development of a pontine cyst after endovascular coil occlusion of a basilar artery trunk aneurysm: case report. Neurosurgery 2003; 52(03):694-699, discussion 698-699

11 Martinez Galdamez M, Saura Lorente P, Palomera Rico A, PérezHigueras A. Intracranial perianeurysmal cyst: still a dilemma. A 
case report with endovascular management. Neuroradiol J 2011; 24(05):743-748

12 Kulwin CG, Gandhi RH, Patel NB, Payner TD. Symptomatic perianeurysmal parenchymal cyst: case illustration. J Neurosurg 2015;123(02):470-471

13 Jayakumar N, Ughratdar I, White E. Obstructive hydrocephalus secondary to a perianeurysmal cyst: a case report. Br J Neurosurg 2019;1-3:1-3

14 Barber SMA-ZN, Al-Zubidi N, Diaz OM, Zhang YJ, Lee AG. Delayed hydrocephalus and perianeurysmal cyst formation after stent- assisted coil embolization of a large, unruptured basilar apex aneurysm: a case report and literature review. Asia Pac J Ophthalmol (Phila) 2014;3(06):354-360

15 Grandhi R, Miller RA, Zwagerman NT, Lunsford LD, Horowitz M. Perianeursymal cyst development after endovascular treatment of a ruptured giant aneurysm. J Neuroimaging 2014;24(05): 515-517

16 Marcoux J, Roy D, Bojanowski MW. Acquired arachnoid cyst after a coil-ruptured aneurysm. Case illustration. J Neurosurg 2002;97 (03):722 